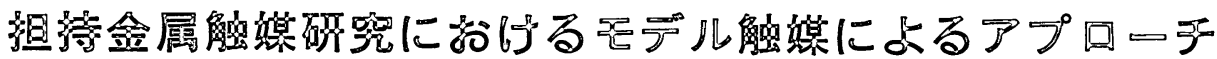

\author{
高須 芳雄 松田 好晴 \\ 山口大学工学部工業化学科 $\bar{T} 755$ 宇部市常盤台 2557 \\ (1980 年 12 月 22 日 受理)
}

\section{An Approach for the Study on Supported Metal Catalysts with Model Catalysts}

\author{
Yoshio Takasu and Yoshiharu Matsuda \\ Department of Industrial Chemistry, Faculty of Engineering, \\ Yamaguchi University, Tokiwadai, Ube 755
}

(Received December 22, 1980)

\begin{abstract}
An application of model catalysts has been presented as one of the methods for investigating the catalytic properties of supported metal catalysts. The model catalysts can be prepared in situ by vacuum evaporation onto an amorphous substrate (film of $\mathrm{SiO}_{2}, \mathrm{Al}_{2} \mathrm{O}_{3}$, or carbon) and studied by such techniques as photoelectron and Auger electron spectroscopy; industrial supported metal catalysts are unsuitable for such techniques using UHV systems. Ensembles prepared in this way offer the possibility of investigating not only the physical properties of particles but also their surface reactivity with simple gases. Apart from the interest in model catalysts, the small metal particles themselves deserve attention; the electronic properties of metal aggregates in size ranges where discrete valence band levels are expected have scarcely been examined. The advantages and application methods of the model catalysts are introduced as well as recent literature on the electronic properties of small metal particles and other approaches for this field.
\end{abstract}

\section{1. はじめに}

電子分光法を中心とする固体表面分析の諸技術は，主 として応用物理学サイドで発展して来たものであるが, 新手法の導入に意欲的な触媒研究者達も早くよりその技 術に注目し，既に多くの成果があげられている。例え ば, 合金触媒や多元酸化物触媒の表面層の組成が内部組 成と同じとは限らない事を AES (Auger Electron Spectroscopy) や XPS (X-ray Photoelectron Spectroscopy) で明らかにしたり, 吸着種と触媒との相互作用を単結晶 を用いて, 原子・電子レベルで把握した LEED (Low Energy Electron Diffraction) や UPS (Ultra-Violet Photoelectron Spectroscopy) の数多くの知見等は, 従 来の手法ではなし得られなかった大きな成果である。こ
の種の研究は量子化学計算も含め今後む継続され, 量・ 質共沉一層発展させられるべきむのであろう。しかし触 媒研究の立場からは，それらはあくまでむ触媒作用の “原点”を探る一方法である為, 他方でその成果を実用 触媒の議論とかみ合わせ得るような “より実用触媒系に 近い研究”が必要な事は言うまであない。その 1 つに, 担持金属触媒という複雑な系への, モデル触媒によるア プローチが最近注目されている。それは, 超高真空系内 で作成したシリカ $\left(\mathrm{SiO}_{2}\right)$ などの薄膜上に，金属を微粒 子状に蒸着したあのを担持金属触媒とみなし，そのキャ ラクタリゼーションを種々の表面分析法により行い, 触 媒反応性との関係を明らかにしようとする方法諭であ る。本稿ではての方法論の意義とその周辺を紹介する。 さて，担持金属触媒とは，またそれにはどのような問題 
が含まれているのであろうか。

\section{2. 表面分析からみた担持金属触媒の諸問題}

担持金属触媒は，自動車の廃ガス処理や石油精製をは じめ, 多くの化学プロセスに用いられている。それら は, 白金, パラジウム, ロジウム等を, シリカ, アルミ ナ $\left(\mathrm{Al}_{2} \mathrm{O}_{3}\right)$, 活性炭 (C), 或いはゼオライト等, 表面積 が大きく, しかも特有の化学的性質をむった担体の上に 微粒子状に分散担持させたものである。担体の種類, 分 散状態, 粒子径等が, 反応活性, 選択性, 寿命等に大き く影響すると言われている。例えば Fig. 1 に示したよ うに, Dartigues らは, $\mathrm{Pt}^{1} / \mathrm{Al}_{2} \mathrm{O}_{3}$ 触媒による 2-メチ ルペンタンの 3-メチルペンタンヘの異性化活性は, 粒 子径が小さい程大であるが, メチルシクロペンタンの水 素化分解活性は, 粒子径が大きい程大である事を見出し ている。粒子径と触媒活性に関する研究は他にむ興味深 (報告があるが2) 5), 未だ統一的, 確定的な結論を得るに は到っていない。その原因は，実用担持金属触媒表面の 複雑性にあると言ってよい。これらの触媒の調製法の典 型的なむのは, 金属の塩の水溶液に担体を浸し, 乾燥後分 解，還元などを行い作製している。従って，金属微粒子 は 3 次元的に分散しており，加多孔性担体ゆえに超高 真空系に導入し難く，表面不純物のない試料を得る事は 至難である。白金の超微粒子に吸着している微量の酸素 は，水素還元によっても除去し難いてとが報告されてい る。この様に, 実用触媒系には UPS を始め電子分光法 を中心とする表面分析法を十分に適用出来得ず，その上 $10 \AA$ 以下の粒径観察む容易ではないという, 表面のキ

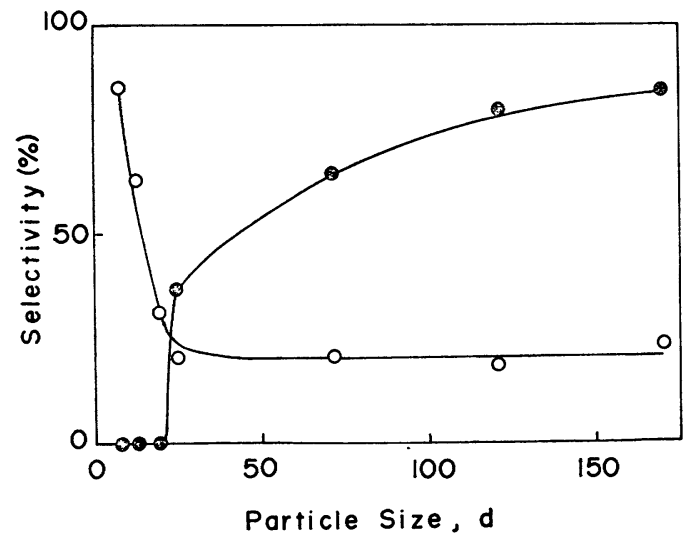

Fig. 1 Contribution of the various mechanisms in (a): isomerization of 2-methylpentane to 3-methylpentane, $\circ$ (percent of cyclic mechanism); (b): hydrogenolysis of methylcyclopentane, $\odot$ (percent of selective hydrogenolysis). Catalyst : $\mathrm{Pt} / \mathrm{Al}_{2} \mathrm{O}_{3}$.
ヤラクタリゼーションを行う上での重大な困難点があ る。そこで，触媒表面をより “well defined”し得るむ のに近づけようとする視点から，モデル触媒が考え出さ れた。

\section{3. 担持金属触媒モデル}

この触媒は，蒸着膜或いは平面の $\mathrm{SiO}_{2}, \mathrm{Al}_{2} \mathrm{O}_{3}$ ，炭素 等の担体上に低速度で金属を蒸着し，初期に生成する島 構造を触媒粒子とみなす。原理的に面方位の定まった単 結晶面ではない為, 種々の制約はあるものの, UPS, $\mathrm{AES}, \mathrm{XPS}$ ，その他が適用出来，しかも2 次元 (平面) であるので電子顕微鏡観察に極めて有利である。最近実 用化された分解能 $2 \AA$ の電界放射型走査電子顕微鏡も 與味深いが，薄膜担体を使用すれば，透過型電顕が容易 に適用できる。Table 1 にモデル触媒で明らかにされ得 る諸性質を掲げた。この手法による研究では，物理的諸 性質をしらべると共に，特にそれらと反応性との相互関 係を解明することが重要であり，出来得れば同一装置内 にて両測定をするのが望ましい。最近，各種機能を備え た電子分光装置の開発や，試料ガス導入部，エアロック システム等の改良がめざましく，上述の要求は近い将来 不可能ではなくなりつつある。現段階では，モデル触媒 の反応性のみを検討したり ${ }^{6)}$ ，或いは次節で述べるよう に,物理的性質のみが別途に検討されているにすぎない。

\section{4. モデル触媒の物理的諸性質}

先ず，モデル触媒の電子顕微鏡写真の一例を Fig. 2 に示す7)。乙れは超高真空装置内にて雲母板上に, 炭素, $\mathrm{SiO}_{2}$, パラジゥムを順次蒸着し, その後てれを水中に投 じ雲母を除去した後，透過型電子顕微鏡にて観察したも のである。パラジウム粒子が細かく分散しており，担持 金属触媒のモデルとなり得ることを示している。このよ

Table 1 Catalytic characteristics which are able to be examined with the model catalysts

\begin{tabular}{|c|c|c|c|}
\hline \multicolumn{2}{|c|}{ physical properties } & \multicolumn{2}{|c|}{ reactivity } \\
\hline parameter & properties & parameter & properties \\
\hline $\begin{array}{l}\text { metal } \\
\text { substrate }\end{array}$ & \begin{tabular}{|l|} 
particle size \\
particle shape \\
size distribution \\
dispersion \\
valence band \\
structure \\
inner shell \\
structure \\
work function
\end{tabular} & $\begin{array}{l}\text { adsorption } \\
\text { reaction } \\
\text { gas } \\
\text { temperature } \\
\text { pressure }\end{array}$ & $\begin{array}{l}\text { amount of } \\
\text { adsorption } \\
\text { adsorption } \\
\text { state } \\
\text { activity } \\
\text { selectivity }\end{array}$ \\
\hline
\end{tabular}


うなアモルファス基板上での金属粒子成長は，実用触媒 上の問題とあ関連して興味深いあのである ${ }^{8,9) 。 F i g . ~} 3$ は $\mathrm{Pd} / \mathrm{SiO}_{2}$ モデル触媒の UPS スペクトル $(\mathrm{He} \mathrm{II})$ で ある7)。蒸着量が少ない場合は, フェルミ準位よりかな り下に d-準位が現われており，パラジゥム粒子の電子 構造が “atomic”であるととを示唆している。しかし平 均粒径 20〜30 $\mathrm{A}$ (スペクトル e) を境にしてそれ以上 の粒径の場合にはフェルミ準位のすぐ下にピークが現わ れ, “metallic”となる。次に, XPSにより Pd/C, Pt/C 系の価電子帯と $4 \mathrm{~d}_{5 / 2}$ 準位の構造を観察した Mason ら の結果 ${ }^{10)}$ を Fig. 4 亿示す。被覆率の増加に伴い価電子 帯の半値幅が増大し，かつしきいエネルギーが減少する 原因として, 彼らは次の 3 点をあげている。即ち, スピ
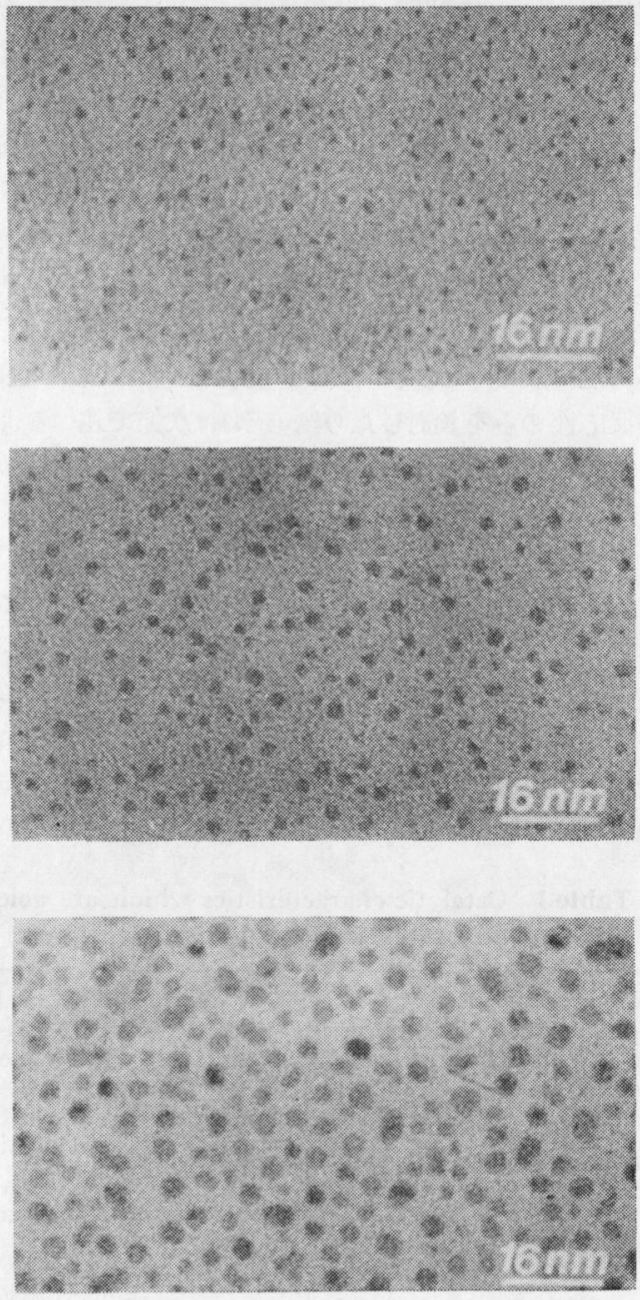

Fig. 2 Electron micrographs from $\mathrm{Pd}$ particle arrays of three different effective thicknesses on a $\mathrm{SiO}_{2}$ substrate. From top to bottom: 1. $0,2.0$ and $5.0 \AA$. The deposition temperature of the $\mathrm{Pd}$ was $300 \mathrm{~K}$.
ンー軌道相互作用の増加, 結晶場による原子的 $\mathrm{d}$-準位 の分裂による二重項の生成，それにブリルアンゾーンを 通しての原子準位のミックシング等である。また，Au/ $\mathrm{SiO}_{2}$ 系をXPS によりしらべた Kim ら ${ }^{11}$ は, Fig. 5 に 示したスペクトルを得た。粒子サイズの減少に伴うエネ ルギーのシフトは, 結晶場ポテンシャル, 緩和エネルギ 一, それに仕事関数等の差異に起因する “matrix shift” と, 価電子帯電子密度の差異に起因する “chemical shift”によると説明している。Fig. 6 は Baetzold ${ }^{12)}$ が 得た $\mathrm{Au} / \mathrm{C}$ 系の $\mathrm{AES}$ スペクトルである。 $\mathrm{N}_{6,7} \mathrm{VV}$ に対 する $\mathrm{O}_{3} \mathrm{VV}$ のピーク位置（ピークの同定は Baetzold と 異なる) は最低被覆率のものでは約 $4 \mathrm{eV}$ 低エネルギー

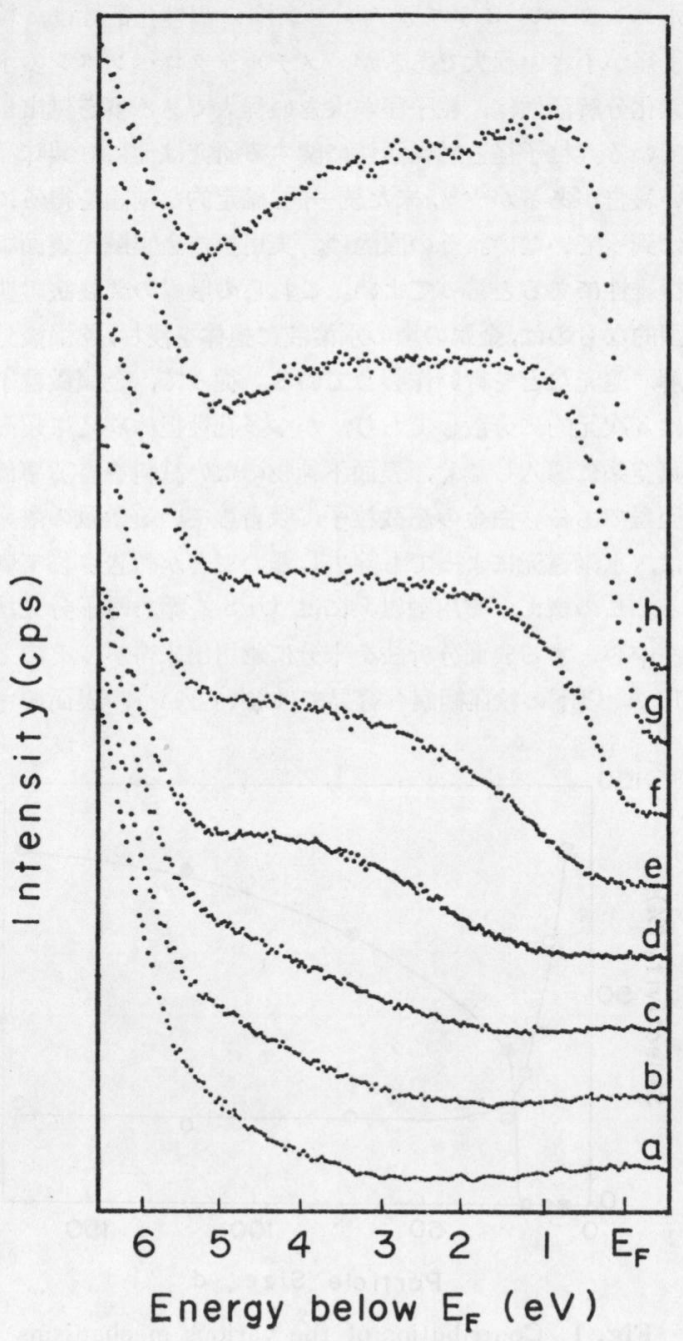

Fig. 3 UPS (He II) spectrum from Pd particle arrays on a $\mathrm{SiO}_{2}$ as a function of increasing particle size. a : clean $\mathrm{SiO}_{2}, \mathrm{~b}: 0.3, \mathrm{c}: 0.7$, d: 2.0 , e: $3.3, f: 6.8, g: 9.8$, and $h: 14 x$ $10^{15} \mathrm{atom} / \mathrm{cm}^{2}$ metal coverage. 


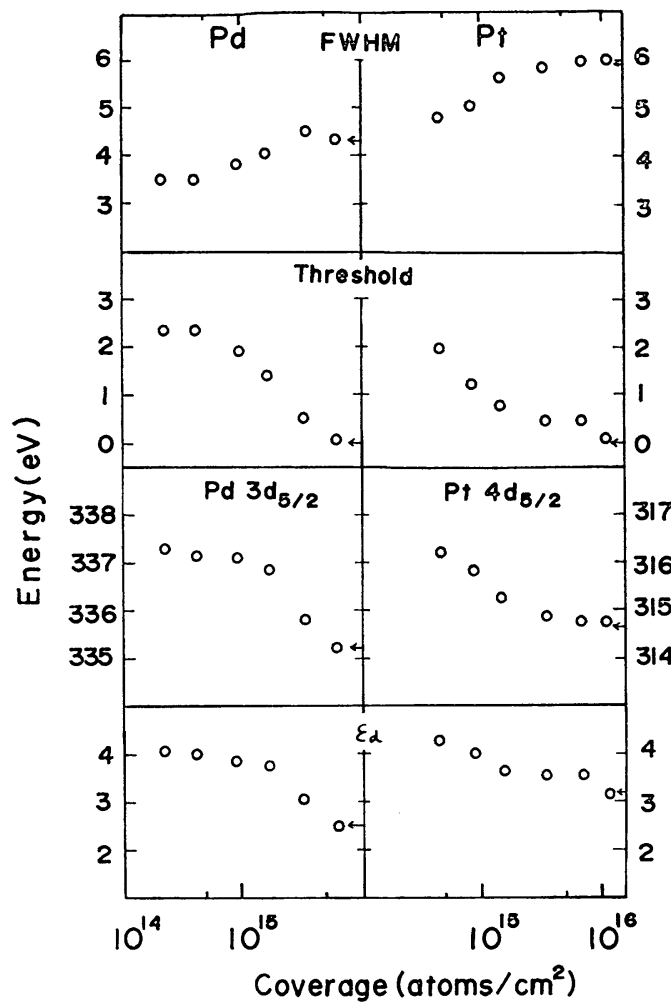

Fig. 4 Variation of valence band width (FWHM), threshold (low binding energy VB edge), core level binding energy, and valence band centroid $\left(\varepsilon_{d}\right)$ with $\mathrm{Pt}$ or $\mathrm{Pd}$ coverage on an amorphous carbon. Bulk values are indicated by arrows. All spectra were recorded on an HP 5950 A ESCA spectrometer using monochromatized $\mathrm{AlK}_{\alpha} \mathrm{X}$-rays.

側にシフトしている。てのようなエネルギーシフトは上 述の XPS の結果と定性的に一致している。又, 最近 Apai ら ${ }^{13)} は$ EXAFS (Extended X-ray-Absorption Fine Structure) を, $\mathrm{Ni} / \mathrm{C} と \mathrm{Cu} / \mathrm{C}$ の両系に適用した。

Fig. 7 と Fig. 8 亿示されているように, 微小粒子程最 近接原子間距離が縮少し, かつ K-吸収端エネルギーの 増加がみられる。彼らは，それは粒子が小さくなるにつ れ表面効果が相対的に大きくなり，金属原子がより自由 原子的配列をとる為だとしている。

以上紹介して来た如く，モデル触媒の金属微粒子は， かなり小さい場合 (<20 ̊ )一上述の場合, 粒径が測定 されていないものも多い一一その電子構造は “atomic” であり,しかも基板の影響は大きく, 粒径が大きい場合と の差異はかなりのものである。従って，触媒反応特性は 金属粒子径や担体の種類に依存することが当然考えられ るが，今のところその相互関係をモデル触媒で試みたも のとしては Hamilton らが初期的知見を報告している

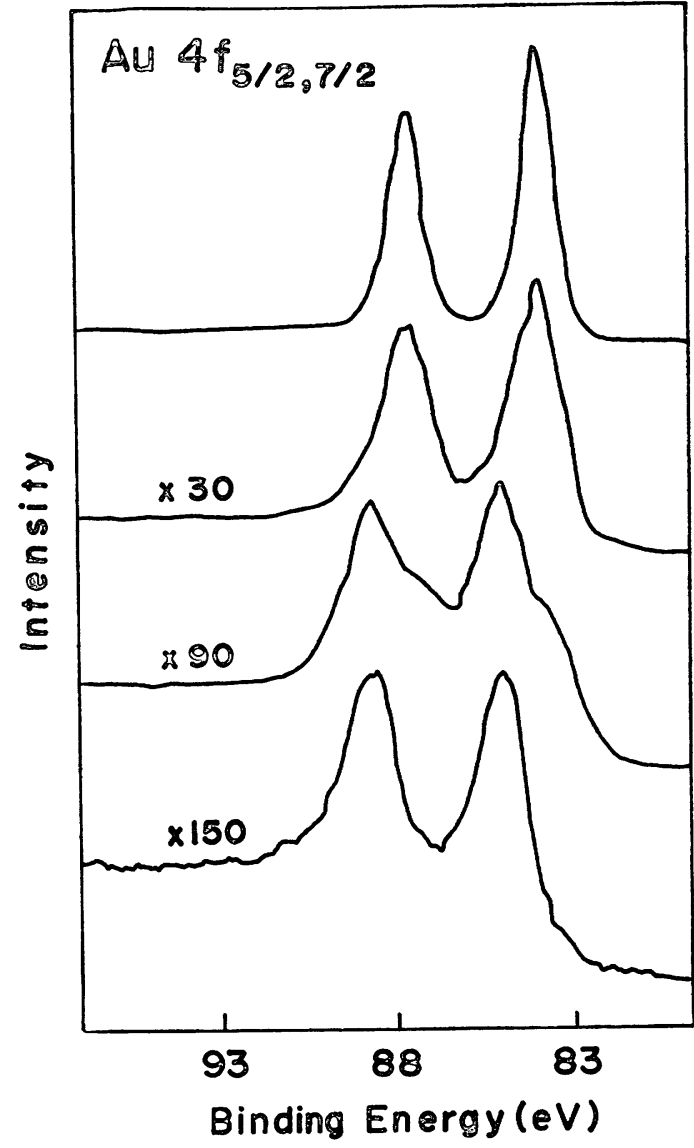

Fig. 5 X-ray photoelectron spectra of $\mathrm{Au}$ with calculated thicknesses of $43,1,0.5$ and 0.2 $\AA$ on $\mathrm{SiO}_{2}$. All spactra were recorded on an HP $5950 \mathrm{~A}$ ESCA spectrometer using monochromatized $\mathrm{AlK}_{\alpha} \mathrm{X}$-rays. The $\mathrm{SiO}_{2}$ sample was grown thermally by heating an $\mathrm{Si}$ chip at $1000^{\circ} \mathrm{C}$ in an $\mathrm{O}_{2}$ furnace.

だけで14)，しかすそれはパラジウム粒子上への亜鉊や二 ッケルの無電解析出という複雑な系における結果にすぎ ない。

\section{5. モデル触媒法と関連する重要な分野}

金属微粒子の作成および粒子成長の理論的解析は，古 くより vacuum evaporation 法により数多く行われて来 た。即ち, 雲母, 金属, 酸化物, アルカリハライド等の 単結晶面上に金属を真空蒸着する方法である ${ }^{15)}$ 。又, 希 ガス中で金属を蒸発させ，担体のない微粒子をつくる gas evaporation 法 ${ }^{16,17)}$, 極低温での希ガス薄膜上に 金属を蒸着し，1 原子から数原子で構成される微粒子を つく matrix isolation 法 ${ }^{18)}$ 興味深い。一方, 金属 微粒子上への $\mathrm{CO}$ の吸着をモデル化した。金属カルボニ 


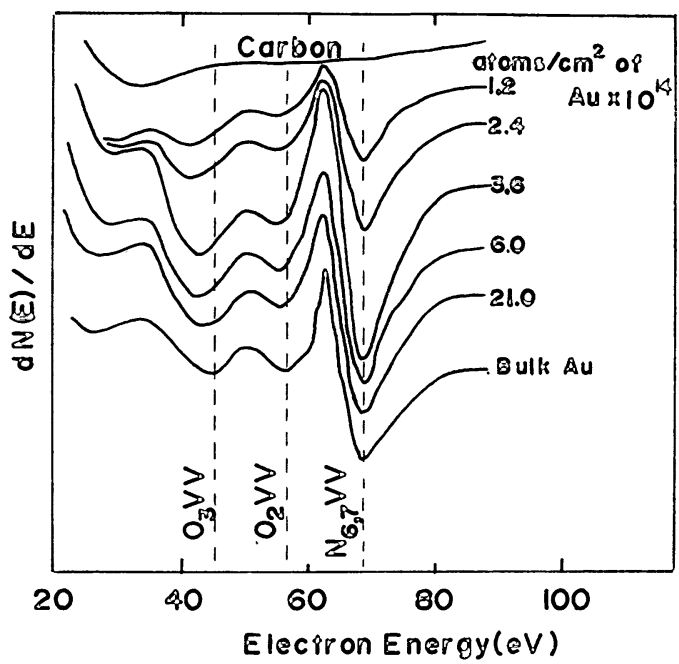

Fig. 6 Low-energy Auger transitions for various $\mathrm{Au}$ coverages on an amorphous carbon. Measured with glancing gun with $3 \mathrm{eV}$ modulation voltage.

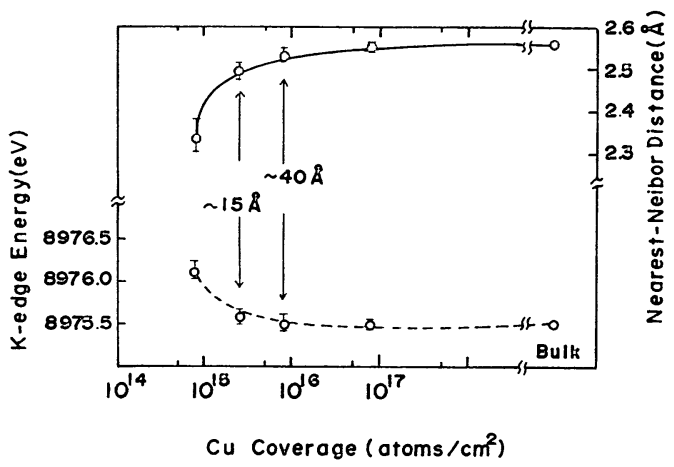

Fig. $7 \mathrm{Cu}-\mathrm{Cu}$ nearest-neighbor distance as a function of evaporated coverage on an amorphous carbon (solid line). Relative change in the onset of the K-edge energy as a function of evaporated coverage (dashed line).

ルの UPS 測定一一例えば $\mathrm{Rh}_{6}(\mathrm{CO})_{16}$ と $\mathrm{Rh}(111) / \mathrm{CO}$ のスペクトルの比較 ${ }^{19}$ —— $\gamma-\mathrm{Al}_{2} \mathrm{O}_{3}$ への $\mathrm{Pt}_{9}(\mathrm{CO})_{18}$ $\left(\mathrm{N}-\mathrm{Et}_{4}\right)_{2}$ 吸着相の IR 測定は ${ }^{20)}$, 金属原子数を厳密に決 めるてとが出来る点で興味深い。更に, 結晶形態学的ア プローチによる結晶系と粒子サイズを関数とした表面の 活性点数の算出法 ${ }^{211}$ は，触媒反応における表面不均一説 を検討する上で重要である。最後に量子化学計算による 金属微粒子の電子構造の計算は, 今後の研究では久かす ことの出来姢情報を提供する。前節に紹介した価電子帯 構造についてむ，一部計算が行われており，実験データ との対比がなされている22,23)。そもそも金属微粒子の電

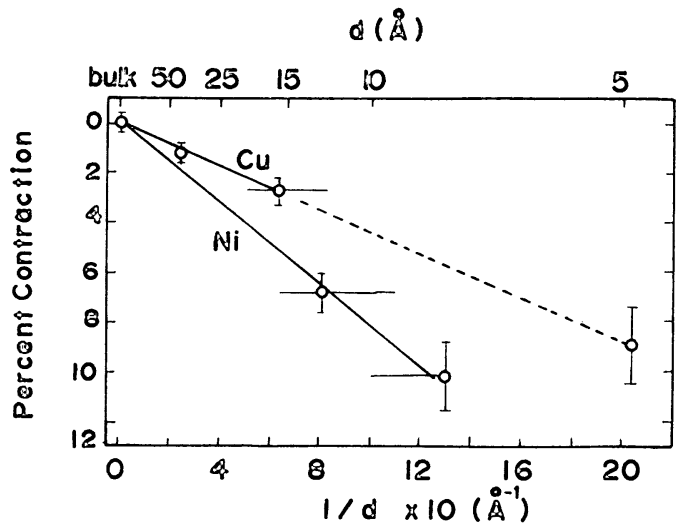

Fig. 8 Plot of percent decrease in nearestneighbor interatomic distance vs. the reciprocal average diameter, d, of various-sized $\mathrm{Cu}$ and $\mathrm{Ni}$ clusters formed on an amorphous carbon. The dashed line extrapolates the $1 / \mathrm{d}$ dependence to the observed percent contraction for the lowest $\mathrm{Cu}$ coverage where clusters are too small to be characterized.

子構造の問題は，古くより金属電子論の立場加ら興味あ るテーマとして提起されていたすのである ${ }^{24)}$ 。

\section{6. おわりに}

以上，モデル化した担持金属触媒の考え方とその周辺 を紹介したが，物性論的検討が先行し，触媒反応性につ いての検討が極めて遅れている．それは実験技術上の困 難さにあよっているが，化学研究者サイドからのアプロ 一チが少ないことに主因があると思われる。触媒研究の 一方法論として, ての種の研究が発展するととを期待し てやまない。なお，本稿と一部関連したむのとして， Anderson ${ }^{25)}$, Takasu $^{26)}$, 荒井 ${ }^{5)}$ おおよ゙その他の総説 ${ }^{27)}$ がある。

\section{文献}

1) J. M. Dartigues, A. Chambellan and F.G. Gault, J. Am. Chem. Soc., 98 (1976) 856.

2) G. C. Bond, Proc. 4th Internl. Congr. Catalysis, Moscow (1968) p. 266.

3) P. H. Otero-Schipper, W. A. Wachter, J. B. Butt, R. L. Burmell and Jr. J. B. Cohen, J. Catalysis, 53 (1978) 414.

4) D. J. C. Yates, L. L. Murrell and E. B. Prestridge, J. Catalysis, 57 (1979) 41.

5）荒井弘通，表面 17 (1979） 675 and 17 (1979) 746.

6) 高須芳雄, 秋丸 勉, 松田好晴, 第 46 回触媒討 論会 $(A)$ ，講演予稿集 (1980) p. 98. 
7) Y. Takasu, R. Unwin, B. Tesche, A. M. Bradshaw and M. Grunze, Surface Science, 77 (1978) 219.

8) J.F. Hamilton and P.C. Logel, Thin Solid Films, 16 (1973) 49.

9) 西山諠行, 荒井正彦, 石川 球, 日化第 41 春季 年会, 講演予稿集 I (1980) p. 494.

10) M. G. Mason, L. J. Gerenser and S. T. Lee, Phys. Rev. Lett., 39 (1977) 288.

11) K. S. Kim and N. Winograd, Chem. Phys. Lett., 30 (1975) 91.

12) R. C. Baetzold, J. Appl. Phys., 47 (1976) 3799.

13) G. Apai, J.F. Hamilton, J. Stohr and A. Thompson, Phys. Rev. Lett., 43 (1979) 165.

14) J. F. Hamilton and P. C. Logel, J. Catalysis, 29 (1973) 253.

15) S. Ino, J. Phys. Soc. Japan, 21 (1966) 346.

16) T. Komoda, Japan. J. Appl. Phys., 7 (1968) 27.

17) K. Kimoto and I. Nishida, J. Phys. Soc. Japan, 42 (1977) 2071.
18) Proc. Internl. Conf. Matrix Isolation Spectroscopy, Berlin (1977), in Ber. Bunsengesell. Phys. Chem., 82 (1978) 1.

19) H. Conrad, G. Ertl, H. Knözinger, J. Küppers and E. E. Latta, Chem. Phys. Lett., 42 (1976) 115.

20) M. Ichikawa, Chem. Lett., 1976, 335.

21) R. van Hardeveld and F. Hartog, Surface Science, 15 (1969) 75.

22) M. Mason and R. C. Baetzold, J. Chem. Phys. 64 (1976) 271.

23) R. C. Baetzold, M. G. Mason and J. F. Hamilton, J. Chem. Phys., 72 (1980) 366.

24) K. Kubo, Comments Solid State Phys., 1(1968) 61.

25) J. R. Anderson, "Structure of Metallic Catalysts", Academic Press, N. Y. (1975) p. 244.

26) Y. Takasu and A. M. Bradshaw, Chem. Phys. Solid \& Surfaces, 7 (1978) 59.

27) 上田良二他「超微粒子」固体物理別冊特集号, 1975 年, アグネ技術センター。 